\title{
Flow-Injection Analysis (FIA) Electrochemical Speciation of Copper in Coastal Waters by Anodic Stripping Voltammetry (ASV)
}

Fei Pan , Rilong Zhu , Haitao Han \& Dawei Pan

To cite this article: Fei Pan , Rilong Zhu , Haitao Han \& Dawei Pan (2020): Flow-Injection Analysis (FIA) Electrochemical Speciation of Copper in Coastal Waters by Anodic Stripping Voltammetry (ASV), Analytical Letters, DOI: 10.1080/00032719.2020.1827262

To link to this article: https://doi.org/10.1080/00032719.2020.1827262

\section{Published online: 06 Oct 2020.}

Submit your article to this journal ๔

\section{Џ Article views: 14}

Q View related articles ¿

\section{View Crossmark data $\llbracket$}




\title{
Flow-Injection Analysis (FIA) Electrochemical Speciation of Copper in Coastal Waters by Anodic Stripping Voltammetry (ASV)
}

\author{
Fei Pan ${ }^{a, b}$, Rilong Zhu ${ }^{c}$, Haitao Han ${ }^{a, b}$, and Dawei Pan ${ }^{a, b}$ \\ ${ }^{a}$ Key Laboratory of Coastal Environmental Processes and Ecological Remediation, Yantai Institute of \\ Coastal Zone Research (YIC), Chinese Academy of Sciences (CAS), Shandong Provincial Key Laboratory

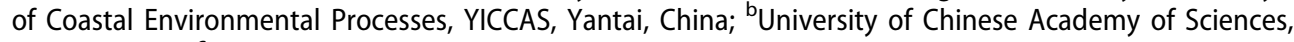 \\ Beijing, China; 'College of Chemistry and Chemical Engineering, Hunan University, Changsha, China
}

\begin{abstract}
A sensitive and precise method for copper $(\mathrm{Cu})$ speciation [electroactive $\mathrm{Cu}(\mathrm{II})$, acid-dissolved $\mathrm{Cu}(0, \mathrm{II})$, and inert $\mathrm{Cu}(0)]$ in coastal waters was developed using flow-injection analysis and electrochemical detection. The reaction is based on a simple redox reaction using a gold nanoparticle modified electrode. The effects of experimental parameters were investigated and optimized. The presence of iron, lead, zinc, cadmium, and aluminum did not interfere with the determination of copper. For total copper, the method detection limit was $1.3 \mathrm{nM}$, and the quantification range was from 5 to $1000 \mathrm{nM}\left(R^{2}\right.$ equal to 0.995), which is sufficiently sensitive for coastal water analysis. A certified reference material was used to characterize the accuracy and good agreement was obtained. The developed method was applied to analyze coastal water samples collected from the Guangdang River, Shandong, China. The $\mathrm{Cu}$ species present are reported and discussed.
\end{abstract}

\section{ARTICLE HISTORY}

Received 6 July 2020 Accepted 19 September 2020

\section{KEYWORDS}

Anodic stripping

voltammetry (ASV); copper speciation; electrochemical analyzer; flow-injection analysis (FIA)

\section{Introduction}

Copper, an essential trace element exists in organisms, plays an important role in the biological cycle (Morel and Price 2003). In phytoplankton, $\mathrm{Cu}$ is mostly present in the chloroplast and primarily participates in stabilizing and protecting the chloroplast and the transmission of electrons (Jensen, Rystad, and Melsom 1976). Cu can improve the flow of carbohydrates in the phytoplankton as well as promote its growth and development. When there is less $\mathrm{Cu}$, the photosynthesis of phytoplankton weakens, which leads to the occurrence of diseases; thus, this condition is not conducive for phytoplankton growth.

However, when there is more $\mathrm{Cu}$, it damages the phytoplankton membrane system, inhibits chlorophyll synthesis, and affects the activity of enzymes. It should be noted that $\mathrm{Cu}$ exists as various species in coastal water and that not all $\mathrm{Cu}$ species can be absorbed and used. Biochemical and toxicological investigations have shown that the 
properties and effects of a trace metal greatly depend on its speciation. In fact, the concentration of total dissolved $\mathrm{Cu}$ does not reflect its bioavailability and toxicity, and the influence of $\mathrm{Cu}$ on the marine environment is closely related to its speciation. Hence, the selective and sensitive detection of $\mathrm{Cu}$ as different species in changing environment like coastal water is of great significance (Küpper et al. 2009).

To the present, several analytical methods have been reported for the determination of $\mathrm{Cu}$, such as atomic absorption spectroscopy (Elci, Kabakc1, and Elci 2015), inductively coupled plasma - atomic emission spectrometry (Dahlquist and Knoll 1978; de Chanvalon et al. 2016), inductively coupled plasma - mass spectrometry (ICP-MS) (Ghaedi, Ahmadi, and Shokrollahi 2007; Kuznetsova, Bychkova, and Timerbaev 2020), capillary electrophoresis (CE) (Chen et al. 2016; Lara et al. 2016), liquid chromatography (LC) (Hu et al. 2003; Sun et al. 2015), and anodic stripping voltammetry (ASV) (Ting et al. 2015; Wan et al. 2015; Chaiyo et al. 2016). The primary methods used for speciation analysis are LC (B'hymer and Caruso 2004; Gao and Ma 2011), CE (Chen et al. 2018; Michalke and Vinković-Vrček 2018; Michalke, Willkommen, and Venkataramani 2019), and ASV (Laglera and Monticelli 2017; Liu et al. 2017; Han et al. 2018; $\mathrm{Hu}$ et al. 2019). However, LC and CE suffer from disadvantages such as complex pretreatment, slow analysis, and high cost. Compared with other methods, ASV is one of the most frequently used and most attractive analytical approaches because of the inherent advantages of simplicity, easy miniaturization, high sensitivity, speed, and lower experimental costs. Moreover, it is widely used for detecting different $\mathrm{Cu}$ species. Gledhill and van den Berg (1995) proposed the concept of electroactive ions and established a method for their detection using electrochemical methods. Different species of copper may be related to biological absorption and utilization.

$\mathrm{Hu}$ classified the copper species in coastal water into these groups: (i) electroactive copper, (ii) acid-soluble copper, (iii) inert copper, and (iv) total dissolved copper (Hu et al. 2019). Gold nanomaterials, which have many superior properties such as large surface area, high electrical conductivity, and good electro-catalytic performance, are widely used as chemically modified electrodes for the determination of different species of copper which can greatly improve the sensitivity and decrease the detection limit. The preparation of gold nanoparticles by electrochemical methods has the advantage of convenience and low-cost that allows online monitoring.

Traditionally, different $\mathrm{Cu}$ species are detected by collecting the water sample, pretreating, and transporting the sample to the laboratory for analysis. However, during transportation or storage, trace amounts of nutrients can lead to contamination, therefore, online monitoring is necessary. Flow-injection analysis (FIA) (Elrod, Johnson, and Coale 1991; Hall and Aller 1992; Croot and Laan 2002) has been extensively used by marine scientists because of its advantages that include low pollution risk, simplicity, high precision, and on-line monitoring. Many reports have focused on this area and combined FIA technology with other methods to detect trace elements. For example, (Lin et al. 2018; Ma et al. 2018; Fang et al. 2019; Ma et al. 2019) combined spectrophotometry and FIA technology.

A novel procedure for the determination of different $\mathrm{Cu}$ species in coastal water is described in this report. Gold nanoparticles were firstly modified on a glass carbon electrode by deposition. This approach was shown to greatly improve the surface area, 
conductivity, and electro-catalytic performance. Importantly, we combined flow injection technology and electrochemical stripping voltammetry to develop an online monitoring system that it has the advantages of lower pollution risk and higher precision. Subsequently, the convenient system is straightforward and inexpensive for $\mathrm{Cu}$ speciation analysis and has considerable potential for ocean shipboard detection in the long-term.

\section{Experimental}

\section{Reagents and materials}

The stock standard solution of $1000 \mathrm{mg} \mathrm{L}^{-1} \mathrm{Cu}$ (II) (purity >99.99\%) was purchased from the National Research Center for Certified Reference Materials (CRMs, Beijing, China), and working standards were prepared after stepwise dilutions. The stock powder of $\mathrm{HAuCl}_{4}$ was supplied by Sinopharm Chemical Reagent Company (Beijing, China). About $1 \mathrm{mM} \mathrm{HAuCl}_{4}$ was prepared using $0.2 \mathrm{M} \mathrm{Na}_{2} \mathrm{SO}_{4}$ for dilution.

Ultrapure water (conductivity of $18.25 \mathrm{M} \Omega \mathrm{cm}$ ) was collected from a Millipore water purification system (Port Washington, NY, USA) and used throughout this study.

Membrane filters for water samples were purchased from Shanghai Xingya Purification Material Factory (Shanghai, China). The sample bottles that were used to hold water were purchased from Xiangyun Plastic Products Factory (Hebei, China).

$\mathrm{HCl}, \mathrm{H}_{2} \mathrm{SO}_{4}$, and $\mathrm{NaCl}$ were purchased from Sinopharm Chemical Reagent Company (Beijing, China). All other reagents were of analytical grade and used without further purification unless otherwise stated.

\section{Instrumentation}

The analyzer was composed of three components: a 8-position selection valve; an injection pump (both of which were purchased from Runze Fluid (Nanjing, China)); and a CHI $1230 \mathrm{C}$ electrochemical system, which was purchased from Chenhua Instruments (Shanghai, China) and equipped with a personal computer for data storage and processing. The measuring unit was a three-electrode system, with gold nanoparticles (AuNPs)modified GCE as the working electrode (diameter of $3 \mathrm{~mm}$, Shanghai, China), a $\mathrm{Ag} /$ $\mathrm{AgCl} / \mathrm{KCl}$ (saturated) electrode as the reference, and a platinum foil as the counter electrode.

We performed scanning electron microscopy (SEM) using a S-4800 electron microscope (Hitachi, Ltd., Japan). A YSI portable multi-parameter water quality measuring instrument was employed (YSI, USA) to monitor various parameters.

Microscopic images of the working electrode were obtained by field effect scanning electron microscopy (FESEM) using a FE SEM S-4800 instrument (Hitachi, USA).

\section{Sample pretreatment}

The samples used in this work were collected from Guangdang River near the Forty Mile Bay in Yantai (Figure 1). Collected coastal water samples were divided into two portions, with one directly detected after filtration. The other portion was filtered and acidified to $\mathrm{pH}<2$ and used for determining acid soluble copper and total dissolved 


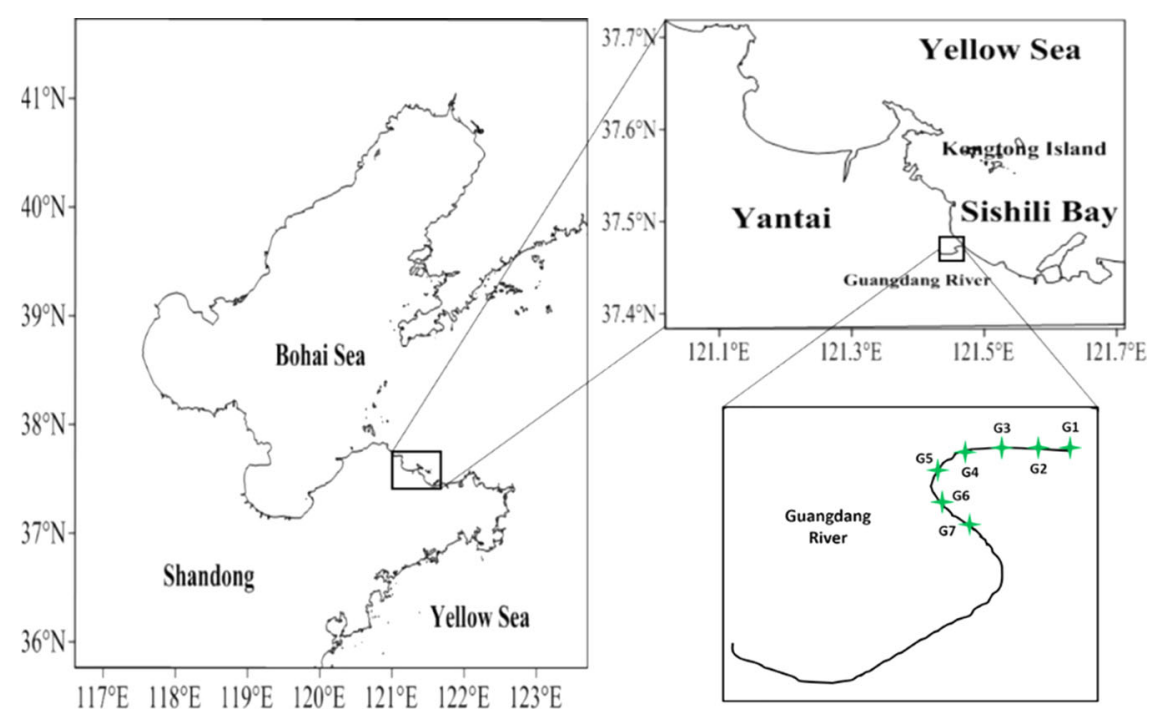

Figure 1. Locations of sampling sites in the Guangdang River.

copper. Note that un-acidified samples were employed for determining electroactive copper.

\section{Description of the apparatus for FIA}

The main detection procedure of on-line monitoring for the speciation analysis of $\mathrm{Cu}$ is schematically illustrated in Figure 2. The detection process includes three components: the sampling system, flow system, and detection system. The core component is a twoway syringe pump that is designed to deliver different volumes of sample to the electrochemical detection cell. The syringe pump is connected to an eight-port switch valve that is connected to the test sample and standard solution. Electrochemical detection systems primarily include home-made electrolytic cells, electrochemical workstations, and commonly used laptop computer. Furthermore, the working electrode was modified via gold nanoparticles that were used for electrochemical detection.

\section{Analytical procedure}

PTFE tubing was used throughout the apparatus with the advantages of resistant to acid and alkali and difficult to adsorb, thus minimizing contamination. To selectively aspirate the sample, the syringe pump was employed. The reagent was added through the switching valve, mixed within the electrochemical cell, and the mixture was electrochemically detected. The valve was positioned in port 1 and a filtered sample was aspirated into the syringe pump. After cleaning the tubing, the sample was injected into the electrochemical cell via port 4 .

To avoid contamination pollution from the previous sample, each aspirate underwent a cleaning process. At the end of each test, in order to prevent the residue of the last sample from interfering with the accurate determination of the next sample, a cleaning should be performed before each injection. Next, the solution was detected by the 


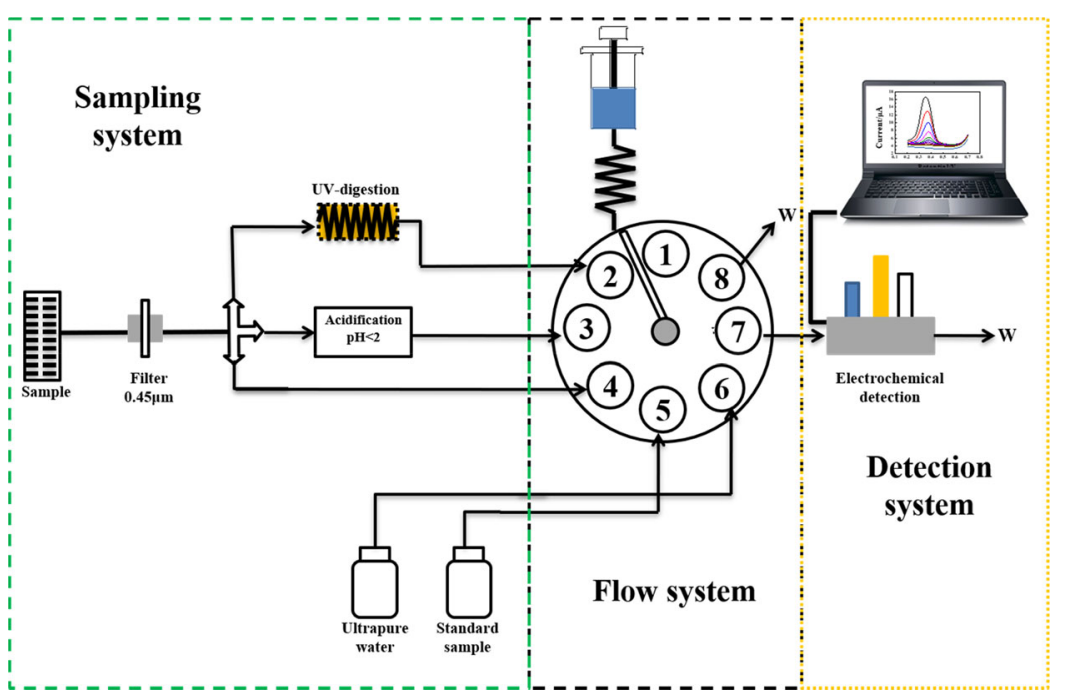

Figure 2. Schematic of the system for Cu (II) speciation.

electrochemical system. The valve was positioned in port 2. The standard solution of copper was aspirated into the syringe pump and was injected into the electrochemical detection via port 4 . The tubing was cleaned, followed by magnetic stirring for $1 \mathrm{~min}$ to mix the standardized solution with the sample. The solution was detected using the electrochemical procedure and this process was repeated twice.

\section{Electrochemical detection processes}

In order to ensure the accuracy of the results, the electrode preparation and testing process were optimized. Although the preparation method of the glassy carbon electrode (GCE) modified by gold nanoparticles is relatively simple, every step must be performed in strict accordance with the requirements; otherwise there may be some variation in the prepared electrodes.

\section{Preparation of AuNPs/GCE}

The samples were analyzed by an electrochemical sensor. Before analysis, a GCE was polished using 0.3 and $0.05 \mu \mathrm{m} \gamma$-alumina slurries, followed by sonication for $1 \mathrm{~min}$ in water and ethanol, respectively. To obtain a stable curve, the treated electrode was activated by cyclic voltammetry $(\mathrm{CV})$ in $0.5 \mathrm{M} \mathrm{H}_{2} \mathrm{SO}_{4}$ using a potential range from -0.2 to $-1.5 \mathrm{~V}$ and a scan speed of $10 \mathrm{mV} / \mathrm{s}$. The gold nanoparticles-modified GCE (AuNPs/ GCE) was prepared by depositing the activated electrode in $1 \mathrm{mM} \mathrm{HAuCl}_{4}$ at a potential of $-0.2 \mathrm{~V}$ potential for $60 \mathrm{~s}$.

\section{Detection process}

The sample was analyzed via ASV. The detection process included accumulation and stripping steps. First, $\mathrm{Cu}$ (II) was reduced to $\mathrm{Cu}$ on the surface of the modified electrode using a potential of $-0.4 \mathrm{~V}$ for $120 \mathrm{~s}$. After balancing for $10 \mathrm{~s}$, the $\mathrm{Cu}$ (II) content 

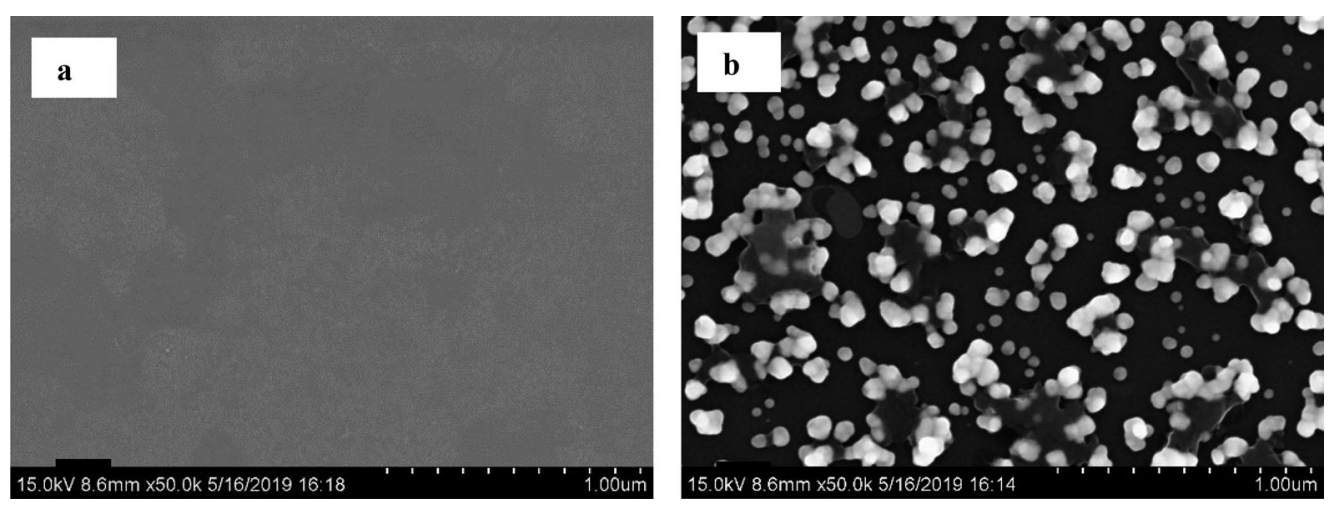

Figure 3. SEM images of the (a) GCE and (b) AuNPs/GCE.

was determined by ASV. The standard addition method was employed for quantitative analysis. All samples were determined three times in parallel: The optimized conditions were an initial potential of $0.2 \mathrm{~V}$, a final potential of $0.7 \mathrm{~V}$, a frequency of $10 \mathrm{~Hz}$, an amplitude of $0.025 \mathrm{~V}$, and a potential increase of $0.004 \mathrm{~V}$.

The working electrode may be reused by cleaning for $30 \mathrm{~s}$ at $0.5 \mathrm{~V}$, followed by removal of residual $\mathrm{Cu}$ on the surface of the working electrode, and detecting the next sample using the same method.

\section{Results and discussion}

\section{Characterization of AuNPs/GCE}

Morphological studies of the GCE and gold nanoparticles (AuNPs)/GCE were carried out using SEM imaging (Figure 3). Figure 3a,b show that some nanoparticles were successfully distributed on the surface of GCE with an average diameter of approximately $100 \mathrm{~nm}$. To further confirm that these nanoparticles were AuNPs, the modified electrode was characterized by $\mathrm{CV}$ in $0.5 \mathrm{M} \mathrm{H}_{2} \mathrm{SO}_{4}$.

As shown in Figure 4, compared with the bare electrode, the oxidation and reduction peaks of modified AuNPs appeared at approximately 1.3 and $0.95 \mathrm{~V}$, respectively. Furthermore, CV confirmed that the AuNPs were successfully modified on the surface of the electrodes. Therefore, the SEM and CV results demonstrate that the AuNPs were successfully modified on the surface of the GCE with an average diameter of approximately $150 \mathrm{~nm}$.

\section{Optimization of experimental conditions}

In this study, a single factor method for determining $\mathrm{Cu}$ was employed to optimize the experimental conditions, including the gold deposition time, deposition potential, and copper ion deposition time. The optimization experiments were performed in $0.5 \mathrm{M}$ $\mathrm{NaCl}$ with $200 \mathrm{nM} \mathrm{Cu}$ (II).

Figure 5 shows the optimization of the experimental results. Figure $5 \mathrm{a}$ shows that the response signal of current first increases and subsequently decreases with the time of the gold deposition. This phenomenon may occur because of the destruction of the 


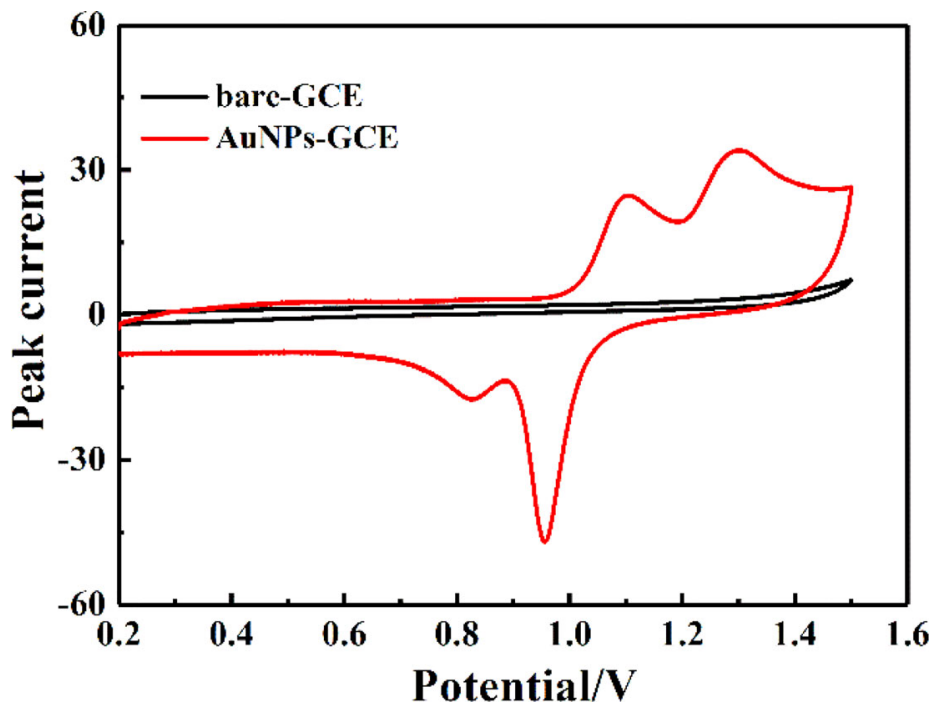

Figure 4. Cyclic voltammograms of GCE and AuNPs/GCE in $0.5 \mathrm{M} \mathrm{H}_{2} \mathrm{SO}_{4}$.

original nanostructure and the obstruction of electron transport with an increase in the number of gold nanoparticles. Therefore, in subsequent experiments, the optimal gold deposition time was $60 \mathrm{~s}$.

Figure $5 \mathrm{~b}$ shows that with the change in deposition potential, the response signal of current increases and then decreases; therefore, $-0.4 \mathrm{~V}$ was selected to be the best deposition potential. Figure $5 \mathrm{c}$ shows that with an increase in deposition time, the current response signal showed an upward trend. Thus, to save time, $180 \mathrm{~s}$ was selected to be the optimum deposition time.

\section{Effect of salinity}

To investigate the influence of salinity on the results and the lifetime of the electrodes, we prepared simulated seawater with different salinity values to characterize its influence. The results show that salinity values from $0 \%$ to $40 \%$ had no influence on the quantitative response of the electrode. High salinity affects the deposition of heavy metal ions on the electrode surface, which may lead to larger error. As the salinity of seawater is approximately $30 \%$, this electrode can be used at a variety of salinity values.

\section{Calibration plot}

There is a linear relationship between the oxidation peak and the concentration of $\mathrm{Cu}$ (II). Under the optimal experimental conditions, the square wave stripping voltammetry curves of $\mathrm{Cu}$ (II) at different concentrations was determined using AuNPs/GCE. As shown in Figure 6, $\mathrm{Cu}$ displayed a strong oxidation peak at the AuNPs/GCE. When the concentration was in the range from 5 to $1000 \mathrm{nM}$, there was a linear relationship with the reduction peak. The linear regression equation is described by $Y=0.1356+0.01114 X, R^{2}=0.995$ with a limit of detection equal to $1.3 \mathrm{nM}$ based upon a signal-to-noise ratio of three. The linear relationship and the detection limit confirm 

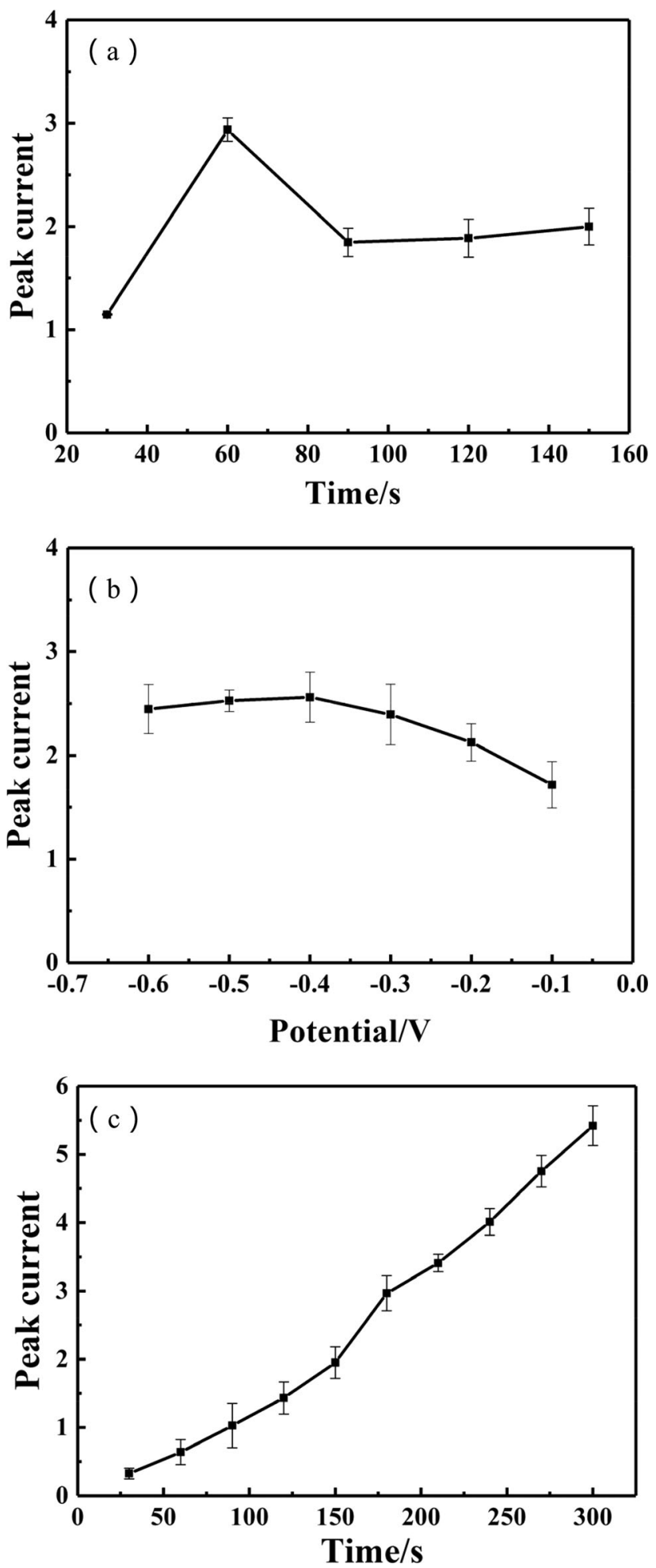

Figure 5. Influence of the (a) deposition time of gold, (b) deposition potential, and (c) deposition time of copper on the stripping peak current of $\mathrm{Cu}$ (II) at the AuNPs/GCE. 


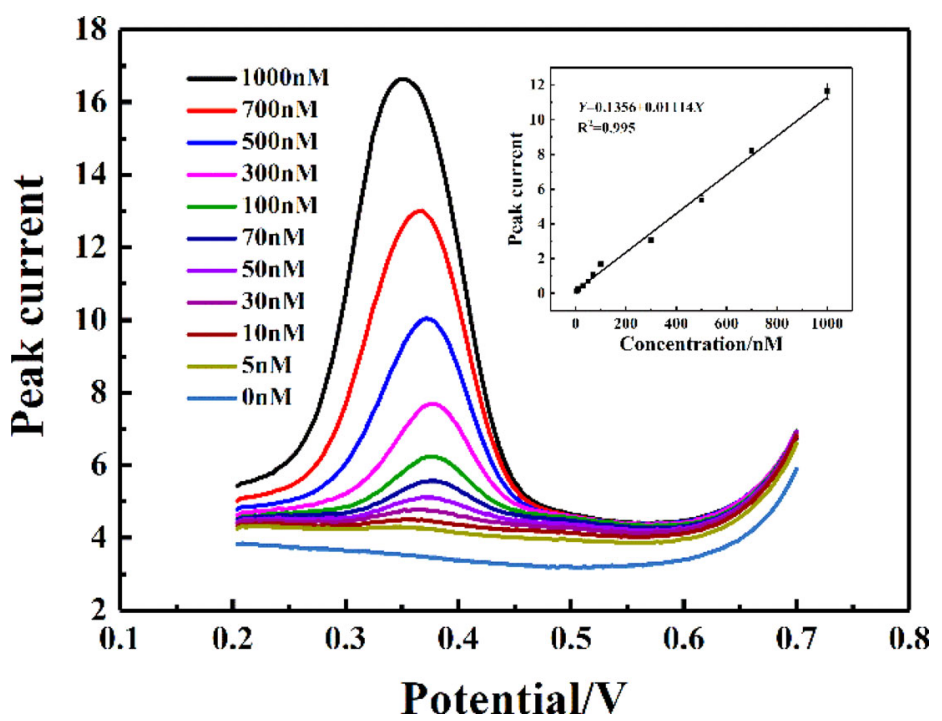

Figure 6. Cu (II) voltammograms on the AuNPs/GCE. The concentrations of $\mathrm{Cu}$ (II) were from 5 to $1000 \mathrm{nM}$ in $0.5 \mathrm{M} \mathrm{NaCl}$. The insert shows the calibration curve for $\mathrm{Cu}$ (II).

that this method is suitable for determining of $\mathrm{Cu}$ (II) in the environmental water samples.

\section{Validation of the analytical method}

We used this analyzer to determine the total dissolved $\mathrm{Cu}$ in the standard reference materials. We compared the results obtained by ICP-MS with the concentration of $\mathrm{Cu}$ in the standard reference materials as well as the real samples determined using the analyzer. The results were in good agreement (Table 1). Because the other methods did not show directly determination of the speciation of $\mathrm{Cu}$, we only compared the total dissolved $\mathrm{Cu}$ to ICP-MS.

\section{Reproducibility, repeatability, and selectivity}

To investigate the stability of the system, the AuNPs/GCE was used to detect Cu (II) in coastal water. The measurements were repeated 20 times. The results showed that relative standard deviation of the peak current was 3.1\%. Even for the real sample analysis, the AuNPs/GCE had good stability. Moreover, the influence of interferences upon the electrode using ions commonly present in environmental water samples. The AuNPs/ GCE was used to determine $200 \mathrm{nM}$ of $\mathrm{Cu}$ (II), within a $5 \%$ error range. The presence of 100 -fold excess of $\mathrm{Na}$ (I), K (I), and $\mathrm{Ca}$ (II), as well as a 30-fold excess of Mn (II), $\mathrm{Al}$ (III), $\mathrm{Pb}$ (II), Cr (II), Fe (III), Zn (II), Cd (II) and 5-fold excess of $\mathrm{Hg}$ (II), Bi (III) had no influence on the measurement.

\section{Method application}

The practicability of the analyzer was characterized by the determination of $\mathrm{Cu}$ species in coastal waters. Other experimental parameters such as the $\mathrm{pH}$, temperature, DO (dissolved oxygen), and salinity were recorded by the YSI analyzer (Table 2). The results in 
Table 1. Analytical results for $\mathrm{Cu}$ (II) in standard reference materials and samples that were collected from Guangdang River near the Sishili Bay in Yantai, China.

\begin{tabular}{lccr}
\hline & \multicolumn{3}{c}{ Concentration of Cu (II) $(\mathrm{ng} / \mathrm{mL})$} \\
\cline { 2 - 4 } Sample & Analyzer & Certified & ICP-MS \\
\hline BY400031 & $15.12 \pm 0.57$ & 15 & $14.39 \pm 0.24$ \\
Real sample 1 & $13.36 \pm 0.91$ & - & $6.20 \pm 0.22$ \\
Real sample 2 & $4.60 \pm 0.68$ & - & $14.54 \pm 1.03$ \\
Real sample 3 & $11.01 \pm 1.31$ & - & \\
\hline
\end{tabular}

Table 2. Distribution of temperature, salinity, $\mathrm{pH}$, and dissolved oxygen in coastal waters of the Guangdang River.

\begin{tabular}{lccccccc}
\hline & $\mathrm{G} 1$ & $\mathrm{G} 2$ & $\mathrm{G} 3$ & $\mathrm{G} 4$ & $\mathrm{G} 5$ & $\mathrm{G} 6$ & $\mathrm{G} 7$ \\
\hline Temperature $\left({ }^{\circ} \mathrm{C}\right)$ & 25 & 25.2 & 28.3 & 24.6 & 25.5 & 26.9 & 24.6 \\
Dissolved oxygen $(\mathrm{mg} / \mathrm{L})$ & 5.34 & 6.03 & 0.44 & 14.37 & 12.25 & 15.25 & 18.77 \\
Salinity (PSU) & 30.5 & 29.28 & 30.52 & 0.43 & 0.4 & 0.41 & 0.39 \\
$\mathrm{pH}$ & 8.51 & 7.96 & 7.62 & 7.95 & 7.97 & 8.16 & 8.07 \\
Inert copper (nM) & $18.55 \pm 0.57$ & $29.04 \pm 0.83$ & $35.27 \pm 1.32$ & $29.66 \pm 1.08$ & $50.17 \pm 1.35$ & $34.28 \pm 1.24$ & $56.12 \pm 1.06$ \\
Electroactive copper (nM) & $31.75 \pm 0.76$ & $25.02 \pm 0.77$ & $57.8 \pm 1.71$ & $123.32 \pm 4.75$ & $97.05 \pm 3.08$ & $84.78 \pm 2.41$ & $84.94 \pm 1.30$ \\
Acid soluble copper (nM) & $159.92 \pm 5.62$ & $18.16 \pm 0.54$ & $76.27 \pm 2.25$ & $45.18 \pm 1.62$ & $23.47 \pm 0.85$ & $23.38 \pm 0.72$ & $85.76 \pm 2.43$ \\
\hline
\end{tabular}

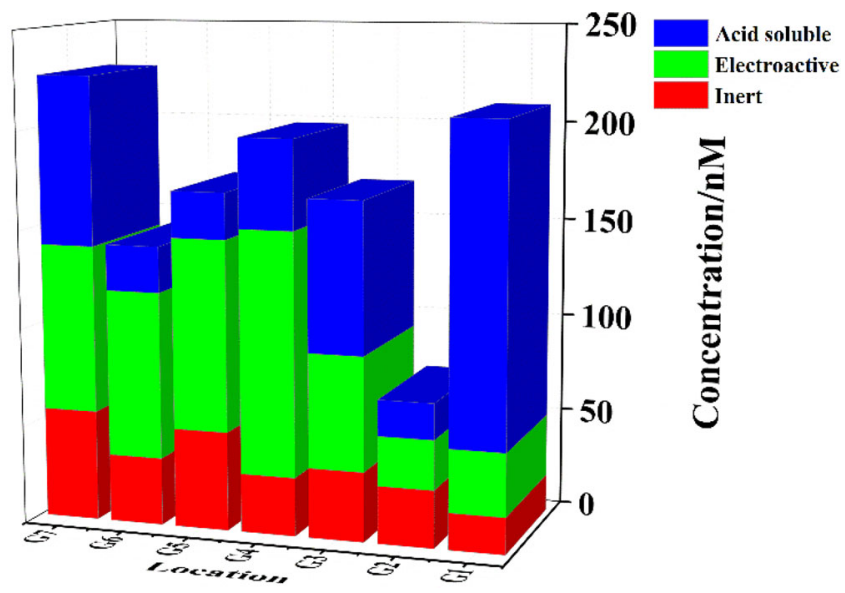

Figure 7. Distribution of $\mathrm{Cu}$ species in the coastal Guangdang River.

Figure 7 show that the dominant form of $\mathrm{Cu}$ is inert $\mathrm{Cu}$ at a concentration of approximately $40 \mathrm{nM}$ due to the stability of $\mathrm{Cu}$. The content of electroactive $\mathrm{Cu}$ is lower in samples G1, G2, and G3, but higher in samples G4, G5, G6, and G7. On the other hand, G1, G2, and G3 had higher salinity values, as well as a considerable phytoplankton in accordance with the change of dissolved oxygen. The lower concentration is related to the salinity or phytoplankton. The concentration is higher in samples G4, G5, G6, and G7 which is also illustrated by changes in salinity and the dissolved oxygen content. In G1, the concentration of acid-dissolved copper is relatively high. Tidal changes in seawater cause the $\mathrm{Cu}$ in the sediment to enter the seawater, which redissolves, and results in a relatively high content. In addition, the salinity and dissolved oxygen also affect the content. Therefore, changes in the concentration of different $\mathrm{Cu}$ species are related to the dissolved oxygen, $\mathrm{pH}$, and salinity. 


\section{Conclusion}

A simple and reliable analyzer has been successfully developed for determining $\mathrm{Cu}$ species in real samples based on electroanalysis with FIA. Moreover, a simple method was established, which was then applied to determine the $\mathrm{Cu}$ species in coastal waters. The measurements in simulated seawater show that salinity has only a slight influence on the sensitivity but no effect on the results. The stability of the electrode was confirmed by multiple measurements of standard solutions. Compared with standard approaches, the developed method had higher accuracy, better sensitivity and improved stability. Hence, for the more accurate and rapid detection of species of metallic elements, it is necessary to develop a real-time online detection approach.

In conclusion, this analyzer satisfied the requirements for future shipboard testing and provided oceanographic data for the $\mathrm{Cu}$ species. Therefore, this technique can provide supporting information for the interactions of trace metal species in environmental waters with organisms.

\section{Funding}

This work was financially supported by the National Key $\mathrm{R} \& \mathrm{D}$ Program of China (2019YFD0901103), the Key Research and Development Plan of Shandong Province (2017GHY215002), and the Key Research and Development Plan of Yantai City (2017ZH096).

\section{References}

B'Hymer, C., and J. A. Caruso. 2004. Arsenic and its speciation analysis using high-performance liquid chromatography and inductively coupled plasma mass spectrometry. Journal of Chromatography A 1045 (1-2):1-13. doi:10.1016/j.chroma.2004.06.016.

Chaiyo, S., A. Apiluk, W. Siangproh, and O. Chailapakul. 2016. High sensitivity and specificity simultaneous determination of lead, cadmium and copper using $\mu \mathrm{PAD}$ with dual electrochemical and colorimetric detection. Sensors and Actuators B: Chemical 233:540-549. doi:10.1016/j. snb.2016.04.109.

Chen, C., X. Li, X. Xie, F. Chang, M. Li, and Z. Zhu. 2016. Highly sensitive detection of copper (I) and copper (II) in cell specimens by CE-UV with large-volume sample stacking. Analytical Methods 8 (21):4272-4276. doi:10.1039/C6AY00.

Chen, Y., L. Chen, X. Wang, Z. Xi, Y. Wu, and F. Fu. 2018. DNA binding in combination with capillary electrophoresis and inductively coupled plasma mass spectrometry for the rapid speciation analysis of mercury. Separation Science Plus 1 (1):52-58. doi:10.1002/sscp.201700015.

Croot, P. L., and P. Laan. 2002. Continuous shipboard determination of Fe (II) in polar waters using flow injection analysis with chemiluminescence detection. Analytica Chimica Acta 466 (2):261-273. doi:10.1016/S0003-2670(02)00596-2.

Dahlquist, R. L., and J. W. Knoll. 1978. Inductively coupled plasma-atomic emission spectrometry: Analysis of biological materials and soils for major, trace, and ultra-trace elements. Applied Spectroscopy 32 (1):1-30. doi:10.1366/000370278774331828.

de Chanvalon, A. T., A. Mouret, J. Knoery, E. Geslin, O. Péron, and E. Metzger. 2016. Manganese, iron and phosphorus cycling in an estuarine mudflat, Loire, France. Journal of Sea Research 118:92-102. doi:10.1016/j.seares.2016.10.004.

Elci, V., E. Kabakc1, and L. Elci. 2015. Solid-phase extractive preconcentration of trace copper as its calmagite anionic chelate using a polyaniline column for flame atomic absorption spectrometric determination. Analytical Letters 48 (4):632-646. doi:10.1080/00032719.2014.956215. 
Elrod, V. A., K. S. Johnson, and K. H. Coale. 1991. Determination of subnanomolar levels of iron (II) and total dissolved iron in seawater by flow injection and analysis with chemiluminescence detection. Analytical Chemistry 63 (9):893-898. doi:10.1021/ac00009a011.

Fang, T., P. Li, K. Lin, N. Chen, Y. Jiang, J. Chen, D. Yuan, and J. Ma. 2019. Simultaneous underway analysis of nitrate and nitrite in estuarine and coastal waters using an automated integrated syringe-pump-based environmental-water analyzer. Analytica Chimica Acta 1076: 100-109. doi:10.1016/j.aca.2019.05.036.

Gao, Z., and X. Ma. 2011. Speciation analysis of mercury in water samples using dispersive liquid-liquid microextraction combined with high-performance liquid chromatography. Analytica Chimica Acta 702 (1):50-55. doi:10.1016/j.aca.2011.06.019.

Ghaedi, M., F. Ahmadi, and A. Shokrollahi. 2007. Simultaneous preconcentration and determination of copper, nickel, cobalt and lead ions content by flame atomic absorption spectrometry. Journal of Hazardous Materials 142 (1-2):272-278. doi:10.1016/j.jhazmat.2006.08.012.

Gledhill, M., and C. M. G. van den Berg. 1995. Measurement of the redox speciation of iron in seawater by catalytic cathodic stripping voltammetry. Marine Chemistry 50 (1-4):51-61. doi:10. 1016/0304-4203(95)00026-N.

Hall, P. J., and R. C. Aller. 1992. Rapid, small-volume, flow injection analysis for $\mathrm{SCO}_{2}$, and $\mathrm{NH}_{4}{ }^{+}$in marine and freshwaters. Limnology and Oceanography 37 (5):1113-1119. doi:10.4319/lo.1992.37.5. 1113.

Han, H. T., W. Y. Tao, X. P. Hu, X. Y. Ding, D. W. Pan, C. C. Wang, and S. H. Xu. 2018. Needle-shaped electrode for speciation analysis of copper in seawater. Electrochimica Acta 289: 474-482. doi:10.1016/j.electacta.2018.08.097.

Hu, Q., G. Yang, Y. Zhao, and J. Yin. 2003. Determination of copper, nickel, cobalt, silver, lead, cadmium, and mercury ions in water by solid-phase extraction and the RP-HPLC with UV-Vis detection. Analytical and Bioanalytical Chemistry 375 (6):831-835. doi:10.1007/s00216-003-1828-y.

Hu, X. P., D. W. Pan, H. P. Han, and C. C. Wang. 2019. Anodic stripping voltammetric analysis of different species of copper in seawater using an electrochemical sensor. Journal of Oceanography 75 (2):149-156. doi:10.1007/s10872-018-0491-z.

Jensen, A., B. Rystad, and S. Melsom. 1976. Heavy metal tolerance of marine phytoplankton. II. copper tolerance of three species in dialysis and batch cultures. Journal of Experimental Marine Biology and Ecology 22 (3):249-256. doi:10.1016/0022-0981(76)90004-6.

Küpper, H., B. Götz, A. Mijovilovich, F. C. Küpper, and W. Meyer-Klaucke. 2009. Complexation and toxicity of copper in higher plants. I. Characterization of copper accumulation, speciation, and toxicity in Crassula helmsii as a new copper accumulator. Plant Physiology 151 (2): 702-714. doi:10.1104/pp.109.139717.

Kuznetsova, O. V., Y. V. Bychkova, and A. R. Timerbaev. 2020. Development and validation of a sector-field inductively coupled plasma - mass spectrometry (ICP-MS) method for analyzing the diagenesis-designating metals in marine sediments. Analytical Letters 53 (4):563-573. doi: $10.1080 / 00032719.2019 .1658200$.

Laglera, L., and D. Monticelli. 2017. Iron detection and speciation in natural waters by electrochemical techniques: A critical review. Current Opinion in Electrochemistry 3 (1):123-129. doi: 10.1016/j.coelec.2017.07.007.

Lara, F. J., D. Airado-Rodríguez, D. Moreno-González, J. F. Huertas-Pérez, and A. M. GarcíaCampaña. 2016. Applications of capillary electrophoresis with chemiluminescence detection in clinical, environmental and food analysis. A review. Analytica Chimica Acta 913:22-40. doi:10. 1016/j.aca.2016.01.046.

Lin, K., J. Pei, P. Li, J. Ma, Q. Li, and D. X. Yuan. 2018. Simultaneous determination of total dissolved nitrogen and total dissolved phosphorus in natural waters with an on-line UV and thermal digestion. Talanta 185:419-426. doi:10.1016/j.talanta.2018.03.085.

Liu, M., D. Pan, W. Pan, Y. Zhu, X. Hu, H. Han, C. Wang, and D. Shen. 2017. In-situ synthesis of reduced graphene oxide/gold nanoparticles modified electrode for speciation analysis of copper in seawater. Talanta 174:500-506. doi:10.1016/j.talanta.2017.06.054. 
Ma, J., H. Shu, B. Yang, R. H. Byrne, and D. X. Yuan. 2019. Spectrophotometric determination of $\mathrm{pH}$ and carbonate ion concentrations in seawater: Choices, constraints and consequences. Analytica Chimica Acta 1081:18-31. doi:10.1016/j.aca.2019.06.024.

Ma, J., P. Li, Z. Chen, K. Lin, N. Chen, Y. Jiang, J. Chen, B. Huang, and D. Yuan. 2018. Development of an integrated syringe-pump-based environmental-water analyzer (iSEA) and application of it for fully automated real-time determination of ammonium in fresh water. Analytical Chemistry 90 (11):6431-6435. doi:10.1021/acs.analchem.8b01490.

Michalke, B., and I. Vinković-Vrček. 2018. Speciation of nano and ionic form of silver with capillary electrophoresis-inductively coupled plasma mass spectrometry. Journal of Chromatography A 1572:162-171. doi:10.1016/j.chroma.2018.08.031.

Michalke, B., D. Willkommen, and V. Venkataramani. 2019. Iron redox speciation analysis using capillary electrophoresis coupled to inductively coupled plasma mass spectrometry (CE-ICP-MS). Frontiers in Chemistry 7:136. doi:10.3389/fchem.2019.00136.

Morel, F. M., and N. M. Price. 2003. The biogeochemical cycles of trace metals in the oceans. Science (New York, N.Y.) 300 (5621):944-947. doi:10.1126/science.1083545.

Sun, M., J. Feng, Y. Bu, and C. Luo. 2015. Highly sensitive copper fiber-in-tube solid-phase microextraction for online selective analysis of polycyclic aromatic hydrocarbons coupled with high performance liquid chromatography. Journal of Chromatography. A 1408:41-48. doi:10. 1016/j.chroma.2015.07.024.

Ting, S. L., S. J. Ee, A. Ananthanarayanan, K. C. Leong, and P. Chen. 2015. Graphene quantum dots functionalized gold nanoparticles for sensitive electrochemical detection of heavy metal ions. Electrochimica Acta 172:7-11. doi:10.1016/j.electacta.2015.01.026.

van den Berg, C. M. G. 1982. Determination of copper complexation with natural organic ligands in seawater by equilibration with $\mathrm{MnO} 2 \mathrm{I}$. Theory. Marine Chemistry 11 (4):307-322. doi:10. 1016/0304-4203(82)90028-7.

Wan, H., Q. Sun, H. Li, F. Sun, N. Hu, and P. Wang. 2015. Screen-printed gold electrode with gold nanoparticles modification for simultaneous electrochemical determination of lead and copper. Sensors and Actuators B: Chemical 209:336-342. doi:10.1016/j.snb.2014.11.127. 